\begin{tabular}{|c|c|c|c|c|c|}
\hline MUNIBE Antropologia-Arkeologia & $n^{\circ} 70$ & $335-349$ & DONOSTIA & 2019 & ISSN 1132-2217 • elSSN 2172-4555 \\
\hline
\end{tabular}

\title{
Platos y cuencos con sal: un ritual funerario de la Edad Moderna y Contemporánea en la Península Ibérica
}

\author{
Dishes and bowls with salt: a funerary ritual of the \\ Modern and Contemporary Age in the Iberian Peninsula
}

PALABRAS CLAVES: Etnología, Arqueología, Osario, Velatorio, Cerámica funeraria.

GAKO-HITZAK: Etnologia, arkeologia, hezurtegia, gaubeila, hiletarako zeramika. KEY WORDS: Ethnology, Archaeology, Ossuary, Wake, Funeral pottery.

Carmen ALONSO-FERNÁNDEZ(1)

\section{RESUMEN}

Desde la Edad Moderna y hasta mediados del siglo XX, en España y otros países de Europa se practicó un ritual funerario a medio camino entre lo religioso y lo pagano cuyo recuerdo en la Península Ibérica aún se rastrea en la tradición oral entre las personas de mayor edad. En el ritual se utilizaba recipientes con sal que se colocaban encima del difunto durante el velatorio o las exequias. Las cerámicas procedentes del osario de la iglesia de Quintanalara (Burgos) -su origen, dispersión y su concepción como elementos cotidianos vs funerarios- sirve de estudio de caso para profundizar en este ritual funerario tan escasamente conocido y estudiado como geográficamente extendido, acotarlo desde el punto de vista cronológico y espacial, e investigar su origen y significado.

\section{LABURPENA}

Aro Modernotik hasi eta XX. mendearen erdialdera arte, Espainian eta Europako beste herrialde batzuetan erlijioaren eta gai paganoen arteko tarteko bidean zegoen hileta-erritu bat egiten zuten, eta Iberiar penintsulako adin handieneko pertsonen artean, haren inguruko oroitzapena oraindik ere jaso daiteke ahozko tradizioan. Erritu horretan, gatzez betetako ontziak erabiltzen zituzten. Hildakoaren gainean jartzen zituzten ontzi haiek gaubeilan edo hiletetan. Quintanalarako (Burgos) elizako hezurtegian jasotako zeramikak (jatorria, sakabanatzea eta sorkuntza eguneroko elementu gisa vs hiletarako elementu gisa) baliagarriak izan dira horren gutxi aztertu eta ezagutu den arren geografiari dagokionez hedatuta egon den hileta-erritu hori sakontzeko kasu-azterketa gisa. Horren arabera, kronologia eta espazio mailako ikuspegitik mugatu eta jatorri eta esanahia aztertu ahal izan dira.

\section{ABSTRACT}

From the Modern Age until the mid-twentieth century, in Spain and other European countries, a funerary ritual was practiced halfway between the religious and the pagan. In the Iberian Peninsula, his memory is still traced in the oral tradition among the elderly. In the ritual were used containers with salt that were placed on top of the deceased during the wake or the funeral. On other occasions, the containers were introduced into the tomb. Although the justification was that the salt prevented the body from swelling, the objective was to prevent the spirit from returning to the body, favouring transit to the beyond or warding off the forces of evil. Sometimes they put open scissors in the shape of a cross on the bowl or the plate. The practice was favoured in Baroque times with the increase of concern for the transit of the soul to the beyond. The fear was based on the belief that the dead do not suddenly leave the world of the living, but reaches an intermediate stage that lasts the time that the body takes to decompose. As long as the dead man's face retains his human features, his soul will be in danger. The salt acts as a protective element. The ritual was applied to both men and women, of all social classes, who lived in rural or urban areas. Among the written testimonies stands out a poem by Federico García Lorca, this describes the ritual in a wake, and a document of the War of Independence, on the funeral of an English general in the monastery of El Escorial (Madrid) in 1812. The pottery from the archaeological excavation of the ossuary of the church of Quintanalara (Burgos) -its origin, dispersion and its conception as everyday elements vs. funerary-, serves as a case study to deepen in this funerary ritual so scarcely known and studied as geographically extended, delimit it from the chronological and spatial point of view, and investigate its origin and meaning. Among the pottery productions are documented typical containers from pottery workshops of Villafeliche (Zaragoza), Talavera de la Reina (Toledo) and Olleros-Olivares (Salamanca-Zamora).

\section{INTRODUCCIÓN}

Desde que nacemos el final de la vida está presente en el horizonte del ciclo vital, por eso el culto a la muerte orbita en todas las civilizaciones y se manifiesta a través del ritual funerario. La ritualización, conformada por objetos, palabras y gestos, tiene como propósito hacer más comprensible el fenómeno natural de morir, y cada sociedad encuentra en esta necesidad la fórmula más adecuada para llevarlo a término. Por este

\footnotetext{
(1) ca@cronossc.es Cronos SC Arqueología y Patrimonio, Centro Europeo de Empresas e Innovación 3. 09007 Burgos.
} 
motivo, los rituales funerarios son una valiosa fuente de comprensión de las culturas y sociedades en tanto en cuanto las individualiza, de ahí la importancia de su estudio y sistematización desde la perspectiva de la arqueología y de la antropología social y cultural.

En la sociedad occidental y a lo largo de nuestra historia reciente, los rituales funerarios cristianos han estado sometidos a cambios y variaciones en su formulación limitados con frecuencia a pequeños aspectos formales. La eliminación progresiva de los ajuares desde la Alta Edad Media fue una constante, reducidos a simples objetos de adorno personal o devocional -rosarios, camándulas, medallas- a medida que nos acercamos a etapas contemporáneas. Sin embargo, en un momento no muy definido de la Edad Moderna -hacia el siglo XVI- apareció una nueva práctica funeraria a medio camino entre lo religioso y lo pagano que podemos rastrear a partir de unas peculiares cerámicas de acompañamiento: los denominados "platos y cuencos de sal"; un fenómeno tan escasamente conocido y estudiado como geográficamente extendido, que comporta un paréntesis entre el ritual funerario precedente y posterior. El estudio de las producciones cerámicas procedentes del osario de la iglesia de San Pantaleón de Quintanalara (Burgos) -su origen, dispersión y concepción como elementos cotidianos vs funerarios- sirve de estudio de caso para profundizar en este ritual funerario tan singular, acotarlo desde el punto de vista cronológico y espacial, y abundar en aspectos esenciales como su origen y significado. El conjunto cerámico fue recuperado durante la intervención arqueológica que realizamos en el lugar en el que hasta fechas recientes se encontraba el osario, junto a la torre del templo.

\section{LA CERÁMICA EN EL RITUAL FUNERARIO DE LA EDAD MODERNA Y CONTEMPORÁNEA}

El descubrimiento a partir de la segunda mitad del siglo XX a lo largo y ancho del territorio peninsular de numerosos recipientes cerámicos en catedrales, iglesias y ermitas -por lo general acumulados en osarios, torres o sacristías-, como consecuencia de la realización de obras de restauración, excavaciones arqueológicas o simples limpiezas, constituyen el vestigio material más evidente de determinadas prácticas rituales de carácter funerario llevadas a cabo durante la Edad Moderna y Contemporánea. Estas prácticas alcanzaron su mayor difusión al amparo del fervor religioso que caracterizó a los siglos XVII y XVIII, dentro de las distintas manifestaciones de la muerte barroca. La muerte, una de las mayores preocupaciones de la época, se convierte durante estos siglos en obsesión bajo la idea de que la vida conduce a la muerte, que vivir es ir muriendo.

El origen de la presencia de algunos de estos recipientes en edificios cultuales puede estar en la cos- tumbre de ofrendar a los muertos pan o trigo, vino, cera y, excepcionalmente, carne y pescado. La práctica, que consistía en depositar dichas ofrendas en la sepultura o sobre el túmulo que hasta principios del siglo XX se erigía para la celebración de las exequias, tenía lugar el día del entierro, a los tres días y en el "cabo de año". Las ofrendas, con carácter de donación pro anima, simbolizaban el banquete funerario y tenían como finalidad la remisión de las penas del purgatorio, pero su destinatario terrenal era el clero (Polanco, 2001: 149) ya que en último término era quien disfrutaba de ellas. A partir del siglo XV aumenta la documentación archivística que recoge esta práctica, generosamente referenciada en los Protocolos Notariales (García-Fernández, 2004). El arraigo de la costumbre de ofrecer pan, vino y cera se rastrea por toda la geografía nacional hasta tiempos no tan lejanos (Blanco, 2005: 68-70), aunque las ofrendas en especie fueron progresivamente sustituidas por aportaciones económicas. En la encuesta del Ateneo de Madrid realizada en 1901-1902, en la provincia de Burgos está atestiguada su pervivencia en Barbadillo de Herreros, Briviesca, Villarcayo o Burgos ciudad (Fernández, 1997: 157-158). El objetivo de la encuesta, promovida por la Sección de Ciencias Morales y Políticas del Ateneo de Madrid, era estudiar "el fenómeno sociológico en el campo de las costumbres populares y en los tres hechos más característicos de la vida: el nacimiento, el matrimonio y la muerte" (Ateneo Literario, Científico y Artístico de Madrid, 1901).

Por su tamaño, algunos de los recipientes a los que nos referimos podrían haber servido para portar estas ofrendas. Entre los recuperados en la iglesia de San Bartolomé de Basardilla (Segovia) hay fuentes, jarras o cántaros (Cruz, 2008: 34) con la capacidad adecuada para tal fin; sin embargo, en la mayoría de los casos documentados, como en la colección de Quintanalara, son pequeños recipientes, por lo general platos y cuencos. Esto no significa que ciertas cantidades de vino no fueran ofrecidas en recipientes de pequeña capacidad. En Zamora, por ejemplo, está constatado el uso de cuartillos -con una capacidad de medio litro- en este tipo de ofrendas (Lorenzo, 1991: 171).

Junto con las ofrendas a los muertos, la administración del sacramento de la extremaunción también puede explicar la existencia de algunas de estas cerámicas. Para la aplicación de los óleos el sacerdote utilizaba unas bolas de estopa que, una vez usadas, depositaba en un plato o cuenco. Para tal fin, la familia proveía de uno de los mejores recipientes que tenía, y cumplida su función no volvía a ser utilizado. Estas cerámicas eran depositadas en algún lugar de la iglesia (Álvaro, 1983: 156; Hernández y Martínez 2014: 39) o acompañaban al difunto en su sepultura, significado este último propuesto para los recipientes aparecidos en algunas tumbas del siglo XVIII de la catedral de Santa María de Vitoria ${ }^{1}$

\footnotetext{
http://www.elcorreo.com/alava/20070701/alava/historia-funeraria-vitoria-20070701.html Fecha de acceso: 21 jun. 2018
} 
El origen doméstico de los platos y cuencos utilizados en la administración de la extremaunción fue objeto de crítica en el sínodo celebrado en Valladolid en 1634: "y porque no es cosa decente que las estopas con que se limpie el santo Oleo de las Unciones se traigan en platos del servicio común, y que después vuelvan á servirse de ellos (...), mandamos que en cada Iglesia se hagan dos platos de estaño o azofar, el uno de ellos un poco mas hondo, que lleven con la Uncion, para traer en ellos dichas estopas, las quales se ha de quemar luego sobre la Pila Bautismal, y hundir sus cenizas por el sumidero de ella" (Obispado de Valladolid, 1634: 98). Obviando el grado de aplicación que pudo tener este precepto, en el inventario de los bienes muebles que la iglesia de Quintanalara tenía en 1772 según el Libro de Fábrica (1767-1820), en relación a la administración de los óleos únicamente figuran "tres crismeras de plata con su caja de madera forrada en barqueta encarnada"; nada se dice de recipientes auxiliares para la unción, por lo que es posible que fuera la familia del moribundo el encargado de facilitarlos.

Al margen de lo expuesto, la explicación de la presencia de buena parte de los recipientes cerámicos que aparecen en contextos cultuales a lo largo y ancho de la geografía peninsular se encuentra en la tradición del uso de la sal en el ritual funerario; pero no se trata de una ofrenda, sino de una herramienta o remedio para conseguir un fin muy concreto. Del mismo modo que el sacramento de la penitencia perdona y cura los pecados del alma -la denominada "sal de penitencia"-, la sal evita la descomposición del cuerpo. La materialización de esta creencia aplicada al ritual consistía en depositar un recipiente con sal sobre el fallecido con el fin de evitar que el espíritu regresara al cuerpo, favorecer el tránsito al más allá o alejar, en definitiva, a las fuerzas del mal; aspiración pagana que se libraba de topar con la censura de la iglesia gracias a la justificación de que la sal evitaba que el cuerpo se hinchase.

La práctica se vio favorecida en época barroca con el incremento de la preocupación por el tránsito del alma al más allá. El temor se fundamentaba en la creencia de que los muertos no abandonan súbitamente el mundo de los vivos, sino que alcanzan un estadio intermedio que dura el tiempo que el cuerpo tarda en descomponerse. Mientas que el rostro del muerto conserve sus rasgos humanos su alma estará en peligro; expuesto a posesiones demoniacas, el espíritu, débil y desorientado, puede ser presa de los ataques del maligno y producir fuertes trastornos en el mundo de los vivos (García, 2010: 154). Por este motivo, antes de la separación definitiva del alma era preciso seguir una serie de pasos ritualizados que comenzaban con el lavado del cadáver y concluían en el amortajamiento. Frecuentemente entre estos pasos estaba la colocación sobre el difunto de un recipiente con sal.

\section{EL RITUAL EN SU CONTEXTO SOCIAL Y CULTURAL}

La sal ha jugado un importante papel en la humanidad desde la Prehistoria, no solo como conservante y condimento de alimentos, también como moneda de cambio, impuesto e incluso casus belli; pero también en el mundo mágico y religioso (Charro, 1998) como símbolo de incorruptibilidad y por su carácter purificador y protector. Muy presente en la cultura hebrea -"el alimento de la sal", "la sal de la sabiduría", "la sal de la alianza" (Chevalier y Gheerbrant, 1990: 858)-, en la doctrina romana ha sido utilizada como vehículo de incorruptibilidad a través de dos usos litúrgicos: la sal bautismal y la sal bendita. En el primer caso, mediante la colocación de un poco de sal en la boca del niño "para que se libre de la podredumbre de los pecados" (Catecismo Romano, 1926: 162); en el segundo, la sal bendita era exortizada y bendecida junto con el agua bendita para las asperges antes de la misa del domingo, y se repartía entre los fieles para uso privado (Herbermman et al., 1916: 1037).

La utilización de la sal durante las exequias también está documentada desde antiguo. El Liber Ordinum (Real Academia de la Historia, signatura: Cod. 56), usado en la liturgia por la iglesia visigoda y mozárabe, insiste en el poder que el demonio ejerce sobre los difuntos; una influencia maligna que puede ser combatida mediante una invocación o la bendición de la tumba, pero también mediante la realización de ritos como dispersar sal sobre el sepulcro mientras se pedía que "ninguna visita demoniaca, ningún espíritu maligno ose profanarlo o ingresar [en él]” (Guilance, 1998: 69).

Pero donde el uso de la sal alcanza mayor difusión es en la tradición popular por sus supuestos poderes sobrenaturales, motivo por lo que está presente de manera recurrente en numerosas prácticas supersticiosas (Charro, 1998). En las relacionadas con el "mal de ojo", en la superstición española es tanto elemento causante (Erkoreka, 2005: 392) como protector (López y Lombardía, 1998: 31). En Latinoamérica, el uso como elemento protector y purificador está ampliamente extendido en rituales que hunden sus raíces en la cultura prehispánica (Wörrle, 1999: 183 y ss). En México, en los altares del Día de los Muertos se colocan pequeños platos con sal como elemento purificador y para evitar la corrupción de las almas (Magaña y Guerra, 2011: 47). En ciertas zonas de Colombia, se practican rituales relacionados con la sal como medida de protección contra las fuerzas malignas: trazar una cruz con sal en los labios de los niños que nacen enfermos o poner sal y unas tijeras a su lado cuando están dormidos para ahuyentar a los malos espíritus (Wörrle, 1999: 184). Bajo la creencia de que el diablo y las fuerzas malignas aborrecen la sal, se enmascara en medidas profilácticas su presencia en el ritual objeto estudio. Símbolo, mito y rito se aúnan para propiciar el tránsito del alma del difunto al más allá. 
El temor al diablo en torno al momento de muerte está presente en el ritual funerario romano a través de otras prácticas. En el siglo XVII, el sacerdote D.J. García (1633: 152, 161) dejó constancia de algunos "Remedios generales contra las tentaciones, y ilusiones del demonio a la hora de la muerte" entre ellos "De cómo se debe tocar la campana en la iglesia" (Fig. 1). Entre las razones de tocar la campana menciona que "extermina y aparta a los demonios aquel sonido de la campana, y los es- panta, que no lo quieren oír". El mismo autor ensalza los beneficios de echar agua bendita al moribundo y a la habitación en la que se encuentra con la finalidad de ahuyentar al demonio. Por otro lado, detrás del acto de cerrar la boca a los difuntos subyacía la intención de preservarlos del ataque del demonio, ya que existía la creencia de que el alma abandonaba el cuerpo por la boca junto con la última exhalación. No cerrarla era dejar una puerta abierta a la entrada de influencias malignas.
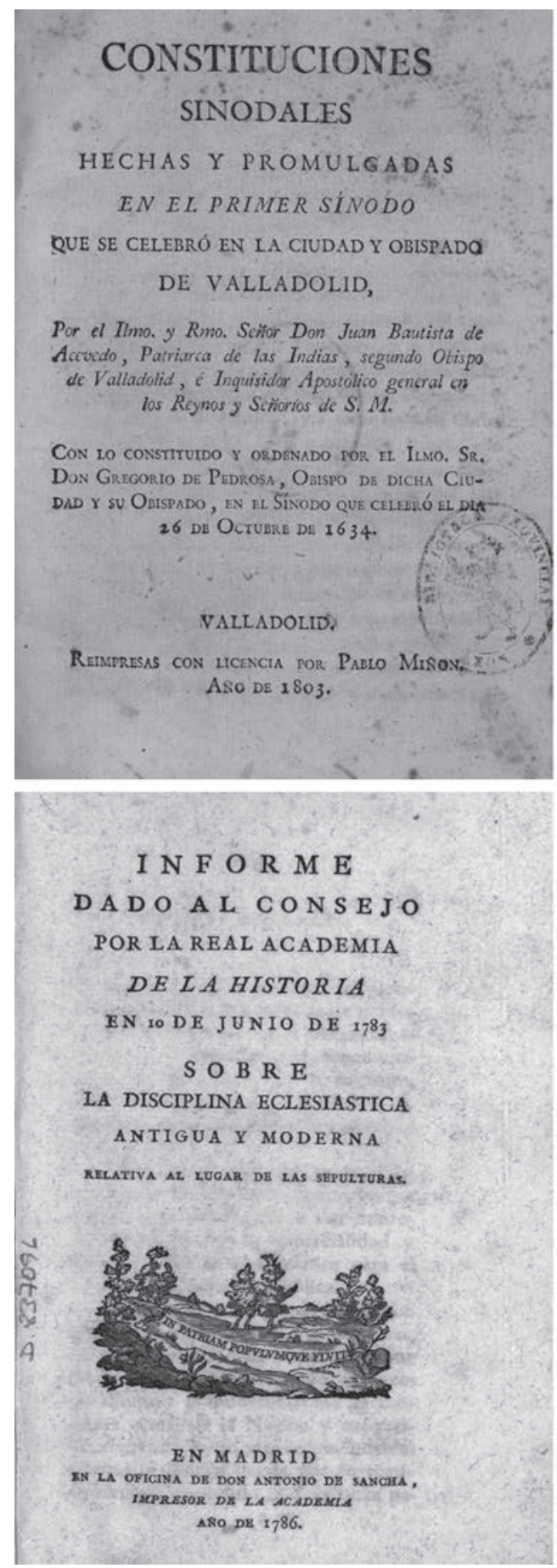
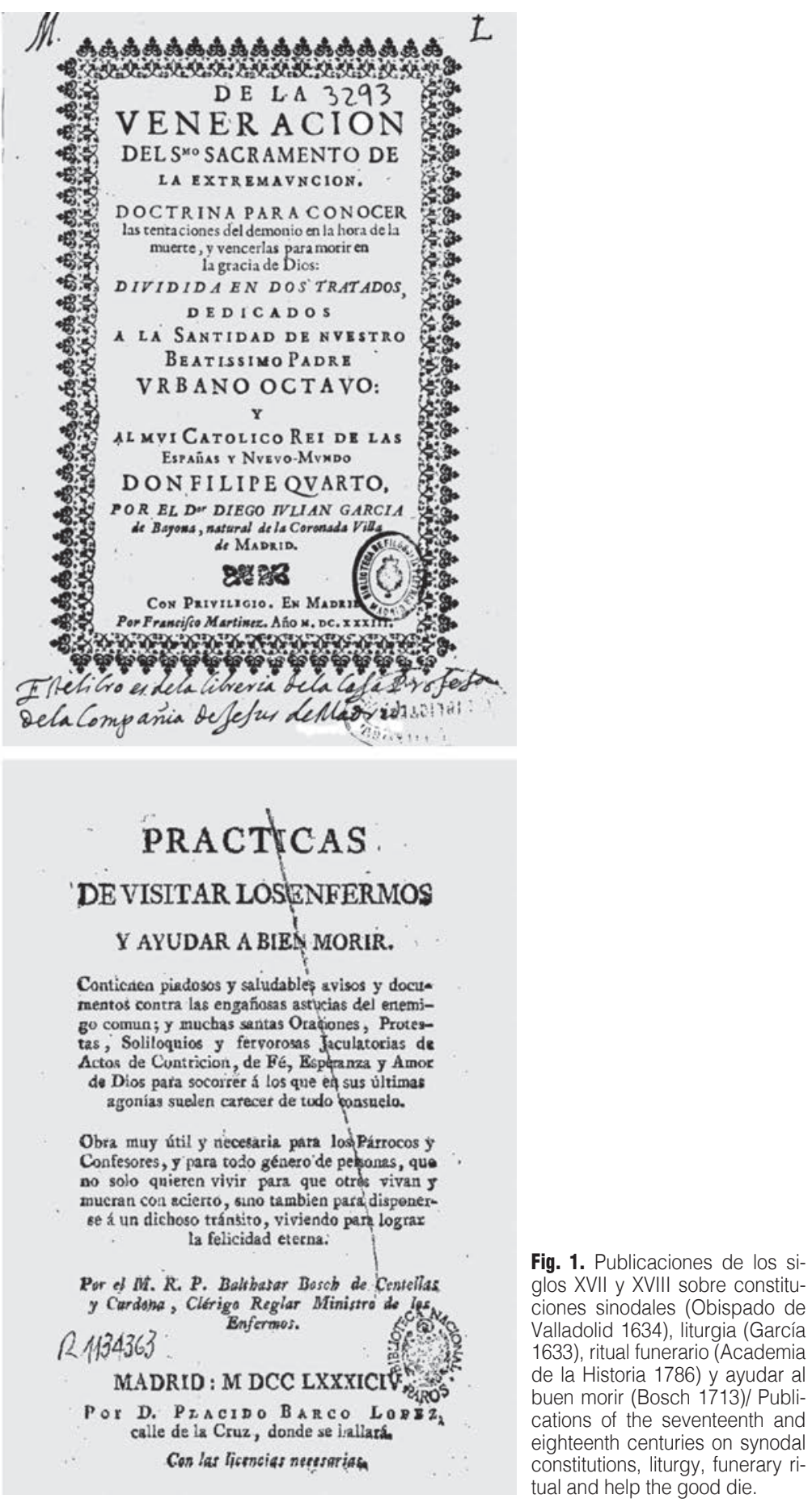
El uso de recipientes con sal en el velatorio o durante la celebración de las exequias está atestiguado en la geografía peninsular gracias a los estudios etnográficos; sin embargo, es muy llamativo el silencio que las fuentes documentales guardan al respecto, particularmente durante el siglo XVIII cuando la tradición debió estar en pleno apogeo. La sociedad de la época, tanto rural como urbana, estaba marcadamente sacralizada. La religión, fundamentada a menudo en la superstición, se vivía profundamente; estaba presente de manera constante, marcaba el ritmo de la vida del individuo y de la mayoría de los actos sociales. El fervor religioso se manifestó en la proliferación de cofradías, principalmente aquellas destinadas a asistir en el trance de la muerte, la construcción de numerosos edificios cultuales, desde iglesias parroquiales a ermitas, o en el encargo de imágenes y retablos. En la pequeña localidad de Quintanalara, según del Libro de Fábrica, solo en el siglo XVII, entre otras obras, se amplió la iglesia con la construcción de dos nuevas naves (1608), se construyeron los retablos de la nave del evangelio (1668) y del altar mayor (1695), se enlosó el templo y se construyó la pila bautismal y el osario (1685).

Dentro de un clima de exaltación religiosa la muerte estaba profundamente ritualizada, también la agonía, alimentada por el temor generalizado de morir solo y sin ceremonia. Por este motivo proliferaron las "prácticas para ayudar al bien morir" (Bosch, 1713) con el objeto de procurar el buen tránsito, en un contexto de reafirmación de la idea del purgatorio, del juicio personal y del final. Desde el amortajamiento a las misas post mortem, todo contaba con su propia ritualidad: el tañido de campanas, el velatorio en la vivienda, la reunión de los allegados, la procesión mortuoria con los cirios, las jaculatorias (García Fernández, 2004). Por este motivo llama la atención la ausencia de testimonios que informen del uso de la sal en el ritual. Ninguna referencia encontramos en obras que se ocuparon específicamente de lo funerario, como el Tratado de los funerales y de las sepulturas de M. de Azero (1736), Instrucciones mortuorias o reglas para los enterramientos y funerales de P. Gómez (1802) o el Informe dado al Consejo por la Real Academia de la Historia (1783) relativa al lugar de las sepulturas.

Por contrapartida, la bibliografía británica de la épo$\mathrm{ca}^{2}$ da testimonio de una práctica de evidente carácter supranacional. En época Georgiana (1714-1837) en Pickering (North Yorkshire) "hay muchos que honran a sus muertos con una bandeja de sal sobre el pecho del cadáver, y todos aquellos amigos que ven a los muertos, y es costumbre común para todos hacer eso, primero tocan el cadáver en la cara o en las manos y luego ponen sus propias manos sobre el plato para perdonar a los muertos cualquier falta o rencor que tuvieran en vida ${ }^{3}$ "
(Home, 1915: 216). En Gales, incluso entre las clases más cultivadas, era costumbre poner el plato con sal para evitar que se hinchase el cadáver (Sikes, 1880: 328). J. Brand (1815: 146) recogió el uso de la misma práctica en Northumberland y Leicestershire (Inglaterra), también en el sur de Irlanda, donde según testimonios de 1777 el plato se colocaba sobre el corazón; y en Escocia, donde se usaba un plato de madera en el que se ponía sal y tierra sin mezclar. La tierra representaba la corruptibilidad del cuerpo y la sal la inmortalidad del alma. Según la Enciclopedia Británica (Encyclopedia Britannica, 1911: 248), en Inglaterra el cadáver era colocado con un plato de sal sobre el pecho debajo de la mesa sobre la que bebían los asistentes al velatorio. La tradición británica debió de ser arraigada a juzgar por el interesante caso documentado en El Escorial. Está recogido en el artículo "Diario de lo ocurrido en el Real Sitio de El Escorial durante la invasión francesa" por M. Cerezal Calvo (1908: 75-76), sobre un manuscrito atribuido al Padre José de Malagón, monje del monasterio durante la Guerra de la Independencia. Dice así: "El 29 de Agosto de 1812 murió en Palacio (...) un General Inglés: Le enterraron el día siguiente en los Jardines frente á la Sacristía (...). Le pusieron una caxa forrada de Vayeta negra, amortajado en una sábana, y con un plato de sal en el vientre (...). El día 7 de Septiembre enterraron, al par del General inglés, un Capitán, en los mismos términos". Todos estos testimonios demuestran que, con diferentes variantes, el ritual se practicó entre personas de diferentes clases sociales.

En nuestro ámbito geográfico contamos con un estremecedor relato de la mano de Federico García Lorca. En un texto de juventud de 1917 titulado Fray Antonio (Poema raro), seguramente a partir de una vivencia personal, el poeta describe un velatorio del siguiente modo: "El muerto estaba embutido en el espantoso cofre con las manos crispadas de un amarillo deshecho. Los pies mostraban unas botas flamantes abotonadas y la cara la tenía piadosamente cubierta con un pañuelo de seda. El abultado vientre, próximo a estallar, soportaba un plato lleno de sal con unas tijeras abiertas puestas allá por una extraña superstición. Antonio se espantó de aquello y, dirigiéndose a un hombre burdo que velaba con indiferencia al cadáver, le preguntó extrañado: '¿Para qué es esto?', y el otro, rascándose la cabeza, musitó soñoliento: 'Eso es pa que no reviente entoavía'" (García-Lorca 1996:763).

\section{MARCO CRONOLÓGICO DEL RITUAL}

A pesar de ser una práctica muy extendida, las primeras referencias documentales sobre el uso de platos y cuencos con sal se rastrean gracias a los estudios etnográficos, aunque las aportadas por la encuesta del

\footnotetext{
2 Información aportada por Da. Margarita Alonso Fernández, a quien agradecemos su contribución.

3 Traducción a partir del texto original en inglés.
} 
Ateneo de Madrid de 1901-1902 son parcas, y una de sus compilaciones más interesantes en este sentido, La fascinación en España: brujas, brujería, amuletos (Salillas, 1906), no deja constancia alguna.

A medio camino entre tradición y ritual, entre lo profiláctico y lo mágico, la práctica está documentada en buena parte del territorio peninsular. Tenía lugar en dos escenarios distintos: durante las exequias, motivo por el que aparecen los recipientes en edificios cultuales, y en el domicilio del fallecido, durante el velatorio, ámbito en el que perduró hasta bien entrado el siglo XX cuando deja de rastrearse en el rito oficiado en la iglesia o en el cementerio. Esto debió suceder hacia mediados del siglo XIX, ya que la mayor parte del registro cerámico documentado conocido no parece superar estas fechas y los testimonios orales aluden fundamentalmente a los velatorios. Por otro lado, atendiendo al volumen de las producciones cerámicas, fue en el siglo XVIII cuando el uso de los recipientes durante las exequias alcanzó mayor difusión.

La práctica en el ámbito eclesiástico se remonta al menos al siglo XVI, así lo indica el registro cerámico recuperado en la iglesia de Nuestra Señora de la Asunción de Socuéllanos (Ciudad Real) (Lucendo et al., 2015), en la iglesia de San Esteban de Villamayor de Campos (Zamora) y en el monasterio de San Zoilo de Carrión de los Condes (Palencia) (Cruz, 2010-12). La supresión en este mismo ámbito, no así en los velatorios, pudo estar condicionada por la publicación de la Real Cédula de 3 de abril de 1787 sobre "Restablecimiento de la Disciplina de la Iglesia en el uso y construcción de cimenterios [sic], según el Ritual Romano". La Real Cédula acababa con la tradición de enterrar en el interior de las iglesias instando a la construcción de cementerios. La medida fue acogida con diversidad de opiniones y acalorados debates, y su puesta en práctica fue más bien tibia (Zaparaín, 1993). Sólo unos años antes, en 1780, la iglesia de San Pantaleón de Quintanalara había estrenado 27 nuevas sepulturas en su interior, como está registrado en el Libro de Fábrica (1767-1820: 40v). La construcción del cementerio tardaría en llegar, no será hasta 1847 cuando se inicie -a destacar que el 15 de mayo de 1804 se promulgó una nueva Real Cédula que insta a la construcción de cementerios-, pero un año después y según el Libro de Fábrica (1821-1849: 59v) se destinan "piedras para las sepulturas de la iglesia" de lo que se deduce que aún se enterraba en el interior.

Posiblemente con los nuevos cementerios construidos en el siglo XIX se introducen cambios en la celebración de las exequias, no solo en Quintanalara, donde el registro cerámico estudiado, efectivamente, no va más allá de mediados de la centuria, sino a nivel nacional, suprimiéndose unas prácticas y dando comienzo otras. Por ejemplo, el cuerpo del fallecido dejó de ser introducido en la iglesia, de modo que la ceremonia tenía lugar en la puerta o en el pórtico donde se instalaba el túmulo; práctica habitual hasta mediados del siglo XX.

\section{CARACTERÍSTICAS DEL RITUAL Y DISTRIBU- CIÓN GEOGRÁFICA}

Como hemos comentado, la práctica tenía lugar en dos escenarios: uno sagrado, durante las exequias, y otro doméstico, durante el velatorio. Del primero apenas hay datos más allá de la presencia de los recipientes cerámicos en contextos eclesiásticos; del segundo, que perduró hasta bien entrado el siglo XX, contamos con informaciones recabadas en estudios etnológicos a partir de testimonios recogidos en el último cuarto del siglo XX en encuestas orales realizadas a personas que aún conocieron la tradición. Desde el punto de vista geográfico se rastrea al menos en Galicia, País Vasco, Navarra, La Rioja, Castilla y León, Castilla-La Mancha, Extremadura, Andalucía, Valencia y Murcia. Es importante reseñar que no se circunscribe al ámbito rural, ya que la arqueología ha constatado su presencia en ciudades como Zamora -iglesia de Santa María la Nueva (Sevillano, 1978: 94)-, Zaragoza -iglesia de San Pablo (Álvaro, 1983: 156) y palacio de la Aljafería (Sáenz, 1998: 73)-, Valladolid-iglesia de San Salvador (Cruz, 2010-12)- y Valencia ${ }^{4}$.

Pese a su amplia distribución geográfica, básicamente el ritual es el mismo, pero se observan algunas particularidades o variaciones sobre varias cuestiones: qué se pone, dónde, a quién y porqué. En esencia consiste en colocar un poco de sal en el interior de un recipiente. Muchos testimonios especifican que se trataba de un plato, pero en el curso bajo del río Mundo y Sierra del Segura (Albacete) el recipiente se sustituía por una bolsa (Jordán e Iniesta, 1996: 335); costumbre que, por testimonios orales, nos consta perdura en la localidad burgalesa de Quintanilla Cabrera, situada a 12 kilómetros de Quintanalara. En Alcozar (Soria), sin embargo, era un recipiente con agua de sal (Aparicio, 2002). Junto con la sal era frecuente la colocación de unas tijeras abiertas, como en el relato de Federico García Lorca; las encontramos en Galicia (Mariño, 2000: 442), Salamanca (Blanco, 2005: 40), Guadalajara (Marco, 2010: 29), Albacete (Jordán e Iniesta, 1996: 335), Soria (Aparicio, 2002), Navarra, Guipuzkoa, Álava, Bizkaia (Barandarian y Manterola, 1996: 205; Blanco, 2005: 40), Cuenca (Díaz y González, 2005: 114), Córdoba (Moreno, 1995: 6) y Murcia (Rodríguez, 2004: 196). Aunque en las tijeras abiertas pude verse el signo de la cruz esconden una profun-

\footnotetext{
${ }^{4}$ https://cnap2017.wordpress.com/arqueologia-de-urgencia/hallazgo-casual-en-la-av-de-portugal-de-valencia-cementerio-y-cripta-de-los-siglos-xvii-y-xviii/ Fecha de acceso: 21 jun. 2018
} 
da simbología. Son interpretadas como un atributo de Átropos, la inflexible, una de las tres Parcas romanas o Moiras griegas, encargada de cortar el hilo de los días. Simbolizan, por tanto, la posible llegada de un fin repentino y el hecho de que la vida depende de los dioses (Chevalier y Gheerbrant, 1990: 260), aunque en el imaginario de la mayoría de los mortales debía subyacer una simbología más sencilla basada en la simple protección.

El recipiente se colocaba por lo general sobre el vientre, también bajo la cama (Flores, 2000: 660), aunque en algunos lugares de Extremadura se hacía sobre el pecho (Domínguez, 1989: 185). Del mismo modo, hay testimonios que indican la colocación en la cabecera en el caso de mujeres que morían en el parto. Así lo encontramos en Garcibuey (Salamanca), donde se acompañaba de las tijeras (Blanco, 2005: 40). En la mayoría de los testimonios no se especifica a qué tipo de personas iba dirigido, ya que se da por hecho que cualquier fallecido podía ser objeto del ritual; sin embargo, en algunas comarcas estaba reservado a las mujeres que fallecían en el parto. Así está documentado en Fuentepelayo (Segovia) (Herrero y Merino, 1996), Los Pedroches (Córdoba) (Moreno, 1995: 6), Campo de Montiel (Ciudad Real) (Villar, 2003: 140) y Torre Pacheco (Murcia) (Rodríguez, 2004: 196).

La justificación de su colocación suele ser evitar la descomposición del cuerpo, algo que, aunque durante el velatorio puede tener sentido, lo pierde durante las exequias, cuando el tiempo que le resta al cadáver para recibir sepultura es mínimo. Lo cierto es que la justificación profiláctica, también aplicada a la presencia de las tijeras, aparece reiteradamente en muchos de los lugares citados, aunque objetivamente no se sostiene. Con el mismo fin, en Salamanca se colocaba una Biblia sobre el cuerpo del fallecido (Blanco, 2005: 40). Evidentemente se esperaba una acción sobrenatural que en principio no tiene la sal, el hierro o un libro, subyaciendo la búsqueda de una protección que iba más allá de evitar la simple descomposición del cuerpo. En el curso bajo del río Mundo y Sierra del Segura (Albacete), se pretendía evitar las manifestación de las fuerzas del mal (Jordán e Iniesta, 1996: 335); en Extremadura, en las tierras al sur del Tajo, que el demonio ronde al difunto (Domínguez, 1989: 185); en Labros (Guadalajara) (Marco, 2010: 29) las tijeras evitaban que los difuntos vagaran y el plato y la sal eran para que, en caso de que esto sucediera, pudieran beber agua y no perdieran el buen sabor; en Garcibuey (Salamanca) si la fallecida estaba embarazada, el plato con sal y las tijeras evitaban que se saliera el feto si acudía alguna bruja al velatorio (Blanco, 2005: 40).

Los testimonios sobre cómo era el ritual durante las exequias son sumamente sucintos. En Navarra y País Vasco hay testimonios que mencionan la retirada del recipiente antes de la inhumación, aunque en Llodio se utilizaba un saquito con sal que sí acompañaba al difunto en su tumba (Barandarian y Manterola, 1996: 205).

\section{LA DOCUMENTACIÓN A TRAVÉS DE LA AR- QUEOLOGÍA}

Que los recipientes eran retirados antes de enterrar al difunto, como por ejemplo se menciona en La Roda (Albacete) (González-Hontoria, 1991: 146), lo constata la ingente cantidad acumulada en osarios, torres de iglesias o sacristías que en ocasiones se cuenta por centenas. Es el caso de las iglesias de Nuestra Señora de la Asunción de Socuéllanos (Ciudad Real) (Lucendo et al., 2015) o San Bartolomé de Basardilla (Segovia) (Cruz, 2008: 34). Las centenas de recipientes procedentes de la iglesia de Sant Nicolau de Bellpuig (Lleida), atribuidos a la extremaunción, fueron recuperados en el interior de un silo (Xandri y González, 2008: 213). Lo cierto es que, una vez cumplida su función, los recipientes eran desechados. Cualquier sitio era bueno, como el interior de un viejo sepulcro gótico (Alonso, 2008), siempre y cuando continuaran en lugar sagrado. Los recipientes no eran reutilizados, pero tampoco siempre eran nuevos. Las marcas de exposición directa al fuego visibles en algunos recipientes de Quintanalara parecen indicar el uso de piezas previamente usadas.

Respecto al tipo de recipientes utilizados, los conjuntos cerámicos conocidos, mayoritariamente enmarcados en el siglo XVIII, están integrados fundamentalmente por piezas de pequeña capacidad, con un claro predominio de platos, cuencos, escudillas y jícaras, tanto de loza como de cerámica común o de basto. Cabe preguntarse si se optaba por un tipo de formas y decoraciones concretas, y si existían alfareros que destinaban parte de la producción para tal fin. Algunos de estos aspectos ya han sido tratados por J.P. Cruz (2010-12). Aunque a juicio del autor algún motivo decorativo, como el omnipresente plantón o palma, pueden tener un significado simbólico, y el repertorio formal es bastante reiterativo, desde nuestro punto de vista no difiere ni en lo formal ni en lo ornamental de los repertorios cerámicos documentados en contextos domésticos. Los platos con el motivo de la palma se hicieron tan populares que se generalizaron en la mayoría de alfares productores de loza en el siglo XVIII. No es de extrañar, por tanto, que aparezcan tan profusamente en los contextos analizados.

Aunque pudieron existir determinados encargos, esto limita la posibilidad de que ciertos alfares dedicaran parte de la producción para fines funerarios, al menos de forma directa pero no indirecta. La presencia de recipientes con defectos de alfar entre la colección de Quintanalara podría atestiguarlo. El mejor ejemplo es un cuenco con una acusada tara de modelado que hace que le cueste sostenerse en pie. El motivo por el que no fue desechado en el alfar puede estar en que ciertas piezas defectuosas se comercializaban a bajo precio con fines funerarios. La pieza mencionada no es única, hay una escudilla con una grieta que la convierte en mercancía de segunda.

El repertorio de provincias donde hay testimonios de la aparición de los recipientes objeto de estudio en contextos cultuales es cada vez más numeroso. En Burgos han sido documentados en Valle de Valdelagu- 
na (Museo Etnográfico de Castilla y León, 2004: 229), iglesia de Nuestra Señora de la Asunción de Villahoz (Alonso, 2008) y en la iglesia de San Nicolás de Bari de Sinovas (Unoveinte, 2010). Posiblemente tuvieron el mismo uso los fragmentos documentados en la excavación arqueológica de la iglesia del despoblado de Revenga (Padilla y Rueda, 2011: 81); por testimonios orales nos consta su aparición en las iglesias de San Esteban Protomártir de Quintanapalla, San Juan Bautista de Riocerezo, Santa Marina de Monasterio de Rodilla y San Juan de Castrojeriz. En Zamora en las Iglesias de Santa María la Nueva (Sevillano, 1978: 94) y Santo Tome (García, 1999: 83), ambas en la capital, así como en la Iglesia de San Esteban de Villamayor de Campos (Zamora), aquí con dataciones entre principios del siglo XVI y el primer tercio del siglo XX (Cruz, 2010-12). En los fondos del Museo Etnográfico de Castilla y León (2004: 230-231) hay varios recipientes procedentes de la provincia de Salamanca. Además de en la iglesia de San Bartolomé de Basardilla (Segovia) (Cruz, 2008), J.P. Cruz (2010-12) refiere la aparición en Palencia -iglesias de San Zoilo de Carrión de los Condes, de Santa Eulalia de Palenzuela y de San Esteban Protomártir de Tabanera de Cerrato-, en Soria -ermita de la Virgen del Vallejo de Alcozar e iglesia de San Miguel Arcángel de San Esteban de Gormaz- y en Valladolid, en la iglesia de San Salvador de la capital, en la de Molpeces y en la de Santa Juliana de Villarmentero.

En La Rioja, donde la documentación etnográfica menciona el rito en Grañón y en la comarca de Haro (La Rioja) (Sáenz, 1998: 72), destacan los repertorios cerámicos aparecidos en la iglesia parroquial de San Andrés de Cameros, de la segunda mitad del siglo XVII y principios del siglo XVIII (Sáenz, 1998), y en la de San Miguel Arcángel de Cuzcurrita de Río Tirón (La Rioja) (Cruz, 2010-12). En el palacio de La Aljafería de Zaragoza aparecieron cerámicas entre los enterramientos de la cripta y la iglesia de San Martín, con una datación entre la segunda mitad del siglo XVII y principios del siglo XVIII (Martín-Bueno et al., 1987: 74-89) que han sido atribuidos a este ritual (Sáenz, 1998: 73). También en Zaragoza, en la iglesia de San Pablo, han tenido lugar hallazgos en este sentido (Álvaro, 1983: 156). En Castilla-La Mancha destacan los mencionados hallazgos de La Roda (Albacete) (González-Hontoria, 1991: 146) y de la iglesia de Nuestra Señora de la Asunción de Socuéllanos (Ciudad Real) de los siglos XVII-XVIII (Lucendo et al., 2015).

Solo en contadas ocasiones los recipientes ha aparecido en el interior de tumbas, lo que parece indicar que fue una práctica poco extendida. En la iglesia de Santa María la Nueva de la ciudad de Zamora, F.V. Sevillano (1978: 94) dio testimonio de la aparición de dos pequeños platos hondos tipo Olivares en el interior de una se- pultura. En la iglesia de Nuestra Señora de la Asunción de Socuéllanos (Ciudad Real) y con una datación de los siglos XVII-XVIII, se documentaron escudillas completas, en uno de los enterramientos hasta 14 ejemplares. Dos de ellas, colocadas bocabajo, contenían una reducción de huesos envueltos en un paño. Por nuestra parte, los testimonios orales que hemos recabado en relación a las iglesias burgalesas de San Esteban Protomártir de Quintanapalla, San Juan Bautista de Riocerezo y Santa Marina de Monasterio de Rodilla, señalan que los recipientes cerámicos se encontraban en el interior de las sepulturas, como también sucede en tumbas del siglo XVIII de la catedral de Santa María de Vitoria ${ }^{5}$.

\section{EL REPERTORIO CERÁMICO DE QUINTANA- LARA (BURGOS)}

Como resultado de la intervención arqueológica que hemos realizado en el lugar que hasta fechas recientes ocupó el osario de la iglesia parroquial de San Pantaleón de Quintanalara (Burgos), han sido recuperados 259 fragmentos cerámicos pertenecientes a recipientes relacionados con el ritual funerario objeto de estudio. Desde el punto de vista metodológico han sido clasificados según sus características técnicas, formales y decorativas con el fin de establecer una tipología. Una vez realizada la clasificación, podemos afirmar que hay un número mínimo de 48 piezas que por el porcentaje conservado permiten ser adscritos a una tipología concreta. La clasificación puede dividirse en cuatro producciones cerámicas -loza, loza entrefina, cerámica común vidriada y cerámica común sin vidriar-, que responden a 14 tipos formales básicos. Cabe destacar que algo más del $31 \%$ de las piezas son platos de loza (Fig. 2). A continuación, detallamos

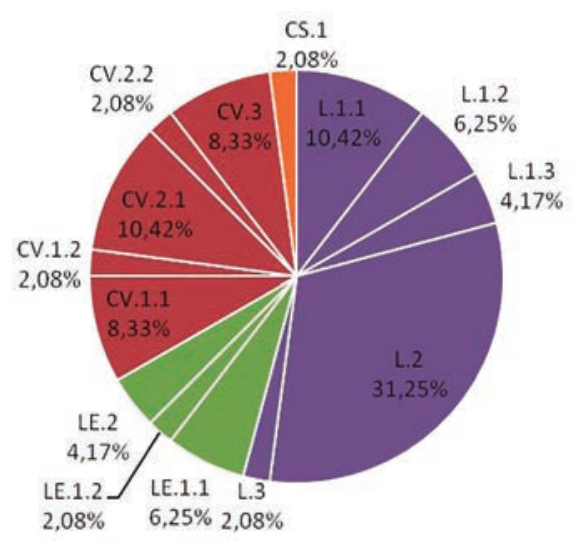

Fig. 2. Representación porcentual de loza (L), loza entrefina (LE), cerámica común vidriada (CV) y cerámica común sin vidriar (CS) procedente del osario de la iglesia de Quintanalara (Burgos)/ Percentage representation of earthenware $(\mathrm{L})$, interfine earthenware $(\mathrm{LE})$, common glazed pottery $(\mathrm{CV})$ and common unglazed pottery (CS) from the ossuary of the church of Quintanalara (Burgos).

\footnotetext{
${ }^{5}$ En este caso atribuidos a la extremaunción http://www.elcorreo.com/alava/20070701/alava/historia-funeraria-vitoria-20070701.html Fecha de acceso: 21 jun. 2018
} 
el repertorio formal recuperado así como las características técnicas y decorativas más reseñables, al tiempo que se ofrecen paralelos de piezas procedentes de contextos similares.

\subsection{Loza (L)}

La loza está representada por jícaras (L1), platos (L2) y cuencos (L3). Las jícaras son pequeños recipientes en forma de vaso utilizados para tomar chocolate, que suelen presentar fondo resaltado mediante un pequeño anillo solero. Iban acompañadas de mancerinas, un plato con pocillo que sujeta al vaso. Su invención se atribuye a Pedro de Toledo y Leyva, marqués de Mancera, a mediados del siglo XVII. A lo largo del siglo XVIII fueron muy popularizadas por la factoría de Alcora (Pitarch y Connors, 2005: 228, 230). Las piezas procedentes de Quintanalara no tienen la cuidada ejecución y decoración de las alcoreñas, son pequeños tazones de loza de inferior calidad y sencilla decoración que llegaron a ser muy populares y fabricados por numerosos alfares.

Ei tipo L.1.1 (Fig. 3) tiene perfil cuenquiforme continuo, borde ligeramente exvasado o vuelto, y fondo con
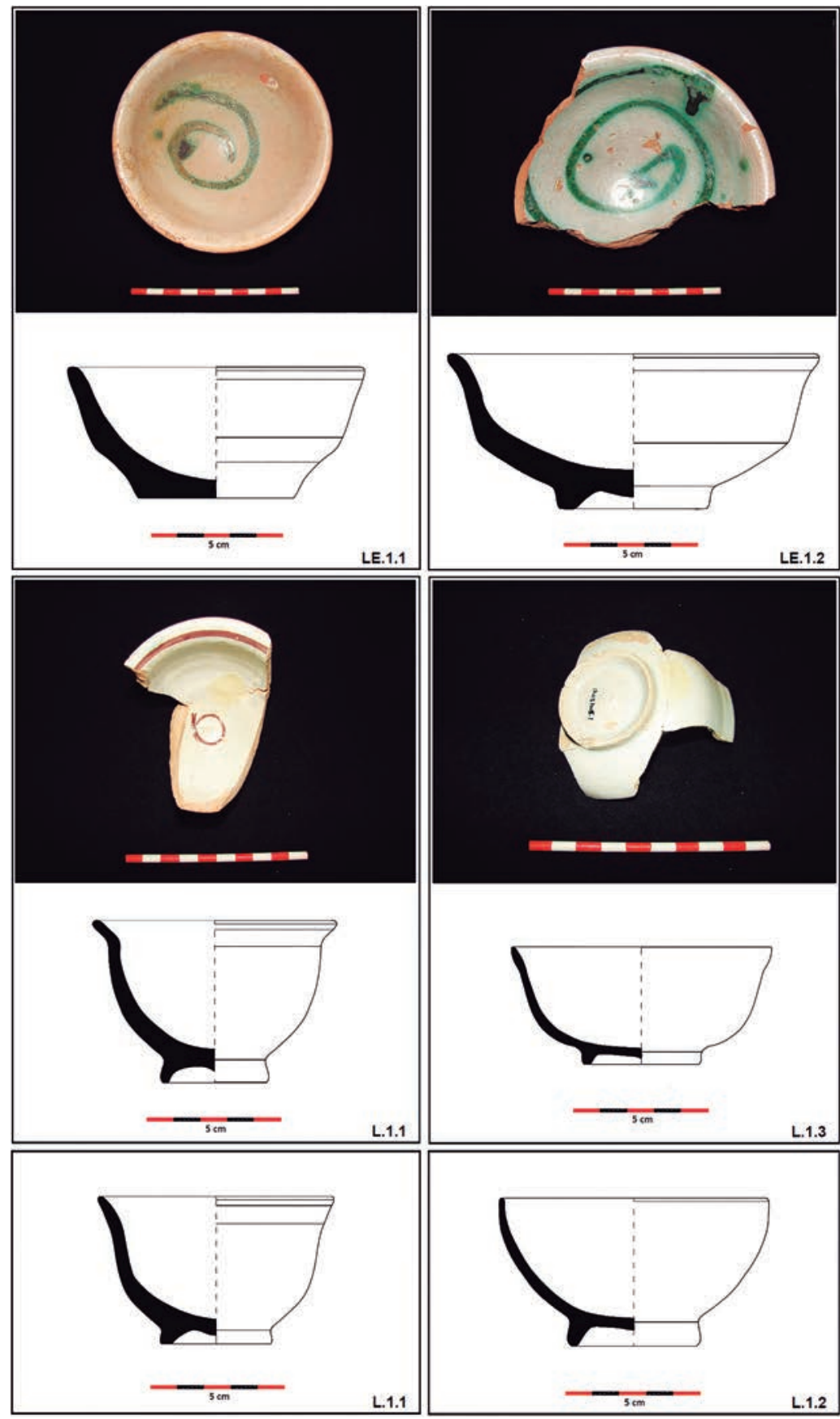

Fig. 3. Loza entrefina (LE) y loza (L) procedente de osario de la iglesia de Quintanalara (Burgos). Dibujos de Margarita Alonso/ Interfine earthenware (LE) and earthenware (L) from the ossuary of the church of Quintanalara (Burgos). Drawings of Margarita Alonso. 
pequeño anillo solero. La pasta es de color rosado-anaranjado, presentando cubierta estannífera de color crema y aplicación irregular que adquiere tonos azulados y violáceos. La decoración más característica es una línea en óxido de manganeso de color morado bajo el labio, tanto en el interior como en el exterior. En el interior llevan un sencillo círculo en el fondo que puede ser doble, o un trazo suelto. Son recipientes del siglo XVIII, de presencia recurrente en contextos similares al analizado. En el Museo Etnológico de Castilla y León (2004: 229) se expone un ejemplar procedente de Valle de Valdelaguna (Burgos), con decoración en morado y procedente de los alfares de Puente del Arzobispo o imitación. En la provincia de Burgos también lo encontramos en la iglesia de Villahoz, con la misma decoración (Alonso, 2008), y en el osario de la iglesia de San Nicolás de Bari de Sinovas, aquí en azul (Unoveinte, 2010). En La Rioja está presente en San Andrés de Cameros (Sáenz, 1998) y en San Miguel de Cuzcurrita de Río Tirón (La Rioja) (Cruz, 2010-12: 568).
El tipo L.1.2 (Fig. 3) está realizado en pasta ferruginosa de color anaranjado. La cubierta estannífera, blanca y densa, puede presentar abundantes burbujas o estar craquelada. Tiene pared continua, perfil hemisférico, labio redondeado y pie con anillo solero. Por lo general la decoración se limita a un ribete azul que cubre el labio al interior y exterior, aunque hay un fondo con decoración floral, quizá de tipo heráldico, en verde. Cronológicamente pudieron alcanzar el siglo XIX. El tipo L.1.3 (Fig. 3) está realizado en pasta de color blanco amarillento. Tiene perfil abierto, ligeramente sinuoso para resaltar el labio, que es redondeado, y fondo con anillo solero. La cubierta estannífera es densa y cubriente, de tono ligeramente grisáceo, un tipo de vidriado que nos remite a la primera mitad del siglo XIX (Moreda et al., 1998: n 450). Una pieza tiene decoración en cobalto mediante trazos poco definidos y una línea que recorre el labio en el interior y en el exterior.

El recipiente más abundante en la colección es el plato de loza (L2) (Fig. 4), de unos 20 cm de diámetro
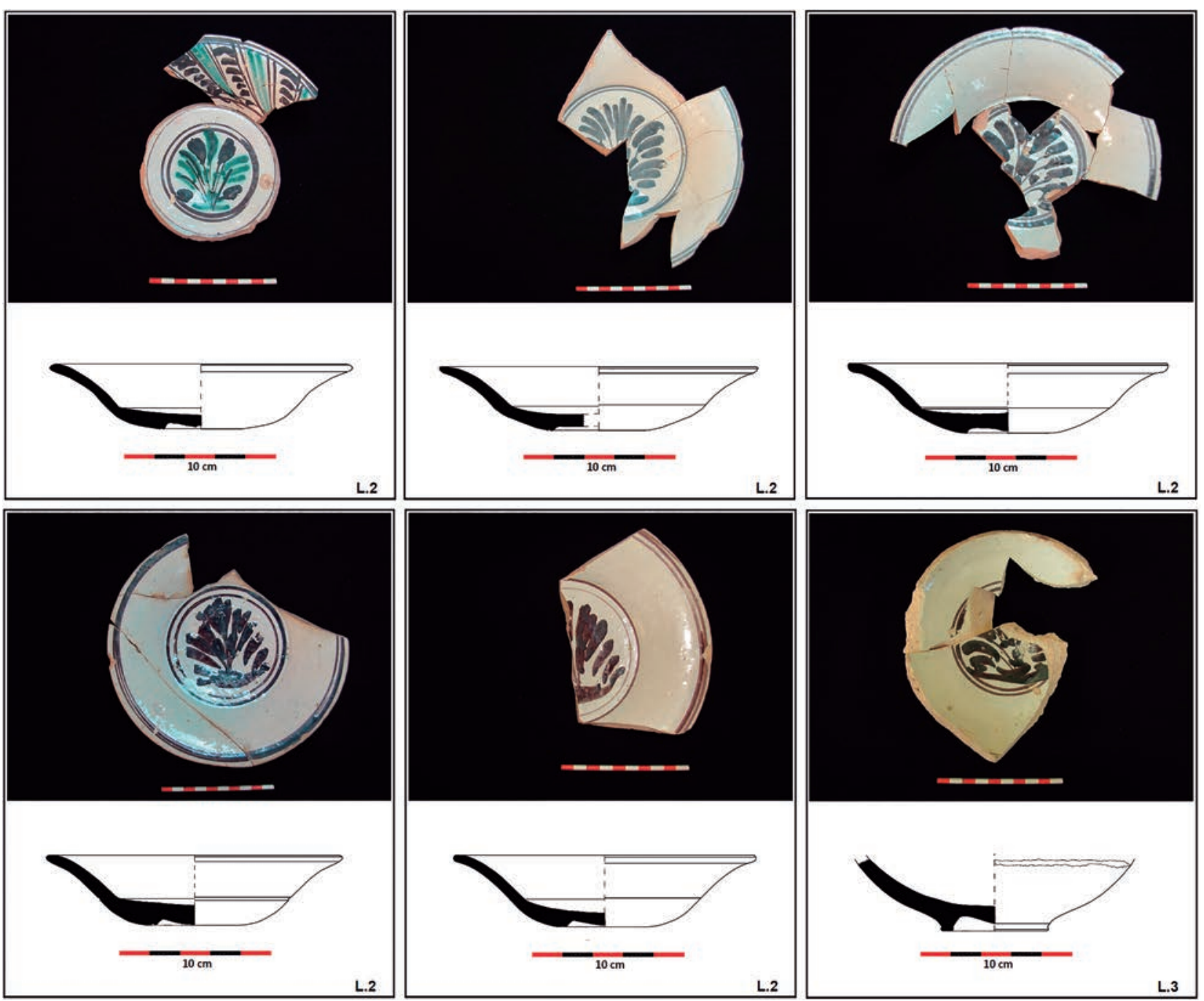

Fig. 4. Platos de loza (L) procedente del osario de la iglesia de Quintanalara (Burgos). Dibujos de Margarita Alonso/ Dishes of earthenware (L) from the ossuary of the church of Quintanalara (Burgos). Drawings of Margarita Alonso. 
y $4 \mathrm{~cm}$ de altura. Desde el punto de vista formal son recipientes de pared continua, abierta y tendida, aunque en el interior se diferencia del arranque del fondo mediante una inflexión. Los bordes, de labio redondeado, son ligeramente vueltos. Los fondos, rehundidos y convexos, aparecen diferenciados en el exterior mediante una ranura. La pasta es de color rosado anaranjado, con cubierta estannífera de aplicación irregular color crema, de tonos azulados o violáceos, que suele presentar vacuolas. La excepción es un plato realizado en pasta de color blanco amarillento, de cubierta estannífera blanca, densa y cubriente, también con abundantes vacuolas. Tiene decoración en azul intenso mediante dos líneas perimetrales que recorren el labio y una tercera que define la unión del ala con el fondo. Se trata de un ejemplar del siglo XIX, el resto, sin embargo, pertenecen mayoritariamente a la centuria anterior y puntualmente al siglo XVII.

Los platos más antiguos comparten decoración de carácter naturalista combinada con elementos más esquemáticos, muy característica de los alfares zaragozanos de Villafeliche (Álvaro, 2003: 167-170). Sobre la cubierta estannífera, aparece pintado a pincel en color verde y morado o amarillo y morado, una mata o ramo en el centro de sencillas hojas distribuidas en abanico o palmeta. Se trata de un conjunto de hojas de trazos esquemáticos sobre finos tallos que nacen de un mismo punto, inscritas dentro de un círculo concéntrico. En el ala se desarrolla una cenefa helicoidal entre pares de listeles concéntricos, compuesta por un motivo de trazos oblicuos en morado, a modo de espiga, y otro semejante a una hoja formada por trazos en verde o amarillo, separados por pares de líneas rectas oblicuas. Villafeliche reprodujo esta decoración entre mediados del siglo XVII y mediados del siglo XVIII. Los platos de Quintanalara están decorados en morado-verde y en morado-amarillo. En morado-verde los encontramos en San Andrés de Cameros (La Rioja) (Sáenz, 1998), y en morado-amarillo San Bartolomé de Basardilla (Cruz, 2008: 39) y en San Nicolás de Bari de Sinovas (Unoveinte, 2010: 48).

Por otro lado, cabe destacar un fragmento de ala decorada en azul con una guirnalda esquemática a modo de cortinaje, de la que parten tallos o motivos vegetales menudos conocidos como "mistos". Esta decoración es típica de los alfares de Villafeliche, que la reprodujeron a lo largo del siglo XVIII. De carácter barroco y realizada en claroscuro azul, se desarrolla durante esta centuria en los talleres de Aragón por influencia de las cerámicas monocromas de Liguria -Génova, Savona y Albisola- (Álvaro, 2003: 170-195). El "tema de los mistos" también se documenta en un plato procedente de la iglesia de San Nicolás de Bari de Sinovas (Unoveinte, 2010: 46) que los autores atribuyen a la serie talaverana de las mariposas.

Exceptuando los ejemplares mencionados, los platos de Quintanalara están decorados mayoritariamente por el motivo de la palma, también denominado del "plantón" (Moreda et al., 1998: 141). El motivo decorativo, en morado de manganeso o azul cobalto, aparece en el centro inscrito en uno o dos círculos concéntricos, mientras que una o dos líneas perimetrales recorren el interior del labio. Se trata de una decoración a base de unas estilizadas hojas de palma que tiene su origen en las series talaveranas de los helechos y de las golondrinas. A su vez, ambas tienen su origen en la copia de porcelanas orientales siguiendo imitaciones de la manufactura de Delft; pero mientras la serie de helechos tiene su momento culminante en el siglo XVII, la de las golondrinas lo hace en el XVIII. En este momento se realizan sobre esmalte menos blanco y los motivos alcanzan la simplificación decorativa (Pleguezuelo, 2002: 453). Como ejemplo de esta simplificación nace el motivo decorativo que nos ocupa.

La palma es quizá el elemento decorativo más característico de la loza popular del siglo XVIII. Alcanzó gran difusión a partir de las series contrahechas (Pleguezuelo, 2001) en numerosos alfares repartidos por la geografía peninsular, entre ellos los de Almazán (Bellido, 2006: 53), Valladolid (Moreda et al., 1998: 95, 98) o Nájera (Martínez, 1994). En contextos similares al estudiado está presente en San Andrés de Cameros (La Rioja) (Sáenz, 1998), Basardilla, San Esteban de Gormaz, Alcozar (Soria) (Cruz, 2010-12: 570) o Sinovas (Unoveinte, 2010)

Los cuencos (L.3) (Fig. 4) tiene paredes de tendencia hemisférica, mientras que el fondo está provisto de anillo solero. La pasta, de color amarillo-rosáceo, está cubierta por un baño estannífero de aplicación irregular, color crema y ligeramente violáceo. Nuevamente aparece la decoración del plantón, en color morado y enmarcado entre dos líneas concéntricas.

\subsection{Loza entrefina o de medio baño (LE)}

La loza entrefina de Quintanalara o de medio baño (Fig. 3) tiene las características propias de la producción de los siglos XVII y XVIII. Está realizada en pastas ferruginosas de color anaranjado y tiene cubierta estannífera poco densa que deja traspasar ligeramente el color de la arcilla. El baño cubre el interior de la pieza, mientras que en el exterior es muy parcial o se limita al labio. La decoración -mediante espirales en óxido de cobre- y las formas -escudillas y platos- son características de los alfares salmantinos y zamoranos. En la calle Olleros de Salamanca se fabricaron entre los siglos XVII y XIX (Lorenzo, 1999: 291-292) y desde finales del siglo XVIII en los alfares de Olivares de Zamora (Villanueva, 2011: 110).

En Quintanalara hay escudillas carenadas de medio baño que responden a dos perfiles diferentes. LE.1.1 tiene cuerpo superior abierto, continuo y labio redondeado. La carena es baja, el cuerpo inferior ligeramente cóncavo y el fondo plano. Lo encontramos en Salamanca (Museo Etnográfico de Castilla y León, 2004: 230), Sinovas (Unoveinte, 2010: 49) y Basardilla (Cruz, 2008: 37). LE.1.2 tiene el cuerpo superior abier- 
to, ligeramente exvasado, y el labio redondeado. La carena es baja, el cuerpo inferior convexo y el fondo con anillo solero. Por último, los platos (LE.2) tienen ala tendida y una ranura que recorre el labio redondeado.

\subsection{Cerámica común vidriada (CV)}

La aparición de cerámica común vidriada en contextos similares a los de Quintanalara es bastante frecuente, siendo la producción mejor representada después de la loza. En el siglo XVIII la encontramos en San Andrés de Cameros (La Rioja) (Sáenz, 1998) y BasardiIla (Cruz, 2008), y ya en el siglo XIX está muy presente en las iglesias de San Esteban Protomartir de Tabanera del Cerrato (Palencia), procedente de los alfares de Astudillo, y en Valladolid ciudad y Molpeceres, aquí de los alfares de Peñafiel (Cruz, 2010-12: 571; García-Benito, 2004: 212). El origen de los recipientes de Quintanalara cabe situarlo en alfares provinciales. En la provincia de Burgos ha habido localidades de tradición alfarera que realizaban cerámica común vidriada o de basto, como Castrojeriz, Aranda de Duero o Huerta del Rey (Seseña, 1997: 147-148; Madoz, 1845-1850: 292, 51, 345). El repertorio que nos ocupa (Fig. 5) está integrado por recipientes de poca capacidad tipo cuenco (CV.1), escudilla (CV.2) y ollita (CV.3), realizados en pastas ferruginosas de color rojizo que contienen abundantes desgrasantes cuarcíticos de calibre fino y medio que proporcionan cierta rugosidad a las piezas pese a estar vidriadas.

Entre los cuencos encontramos perfiles de tendencia cerrada (CV.1.1) y abierta (CV.1.2). En el primer caso son de perfil continuo, borde reentrante, labio redondeado y fondo plano. Tienen cubierta vidriada, total en el interior y parcial en el exterior, en ocasiones rugosa y burbujeante, de color melado o bícroma melada y amarilla. El único perfil completo, que se corresponde con el ejemplar melado, cabe encuadrarlo en el siglo XVIII, el resto son ya del siglo XIX. El único cuenco abierto tiene borde abierto, labio redondeado y fondo plano. La cubierta vidriada, en color melado brillante, cubre la totalidad de la superficie interior y parcialmente la exterior. Presenta una incisión en el interior, en el fondo, y un importante defecto de modelado en la base. Parece una producción del siglo XIX.

Entre las escudilas encontramos dos tipos de perfil: de borde reentrante (CV.2.1) y de labio exvasado (CV.2.2), siempre con el fondo plano. En el primer caso están vidriadas completamente en el interior, en verde oliva y melado, mientras que en el exterior la cubierta se limita al labio y a algunos goterones. Un recipiente de este tipo, melado con decoración en amarillo, recuerda a la tradicional producción palentina de Astudillo. También se documenta en Castrojeriz, lugar al que se trasladaron algunos alfareros procedentes de Astudillo en el siglo XIX (Seseña, 1997: 147-148). En el único recipiente de labio exvasado el vidriado se limita a algunos goterones melados en el exterior. Escudillas de los estilos descritos aparecen en vidriado melado y verde ya en el siglo XVII en Valladolid (Moreda et al., 1998: $n^{\circ}$ 265). En contextos funerarios se recogen en el Museo Etnológico de Castilla y León (2004: 230), en concreto un recipiente del siglo XVII procedente de los alfares de Alba de Tormes. Las piezas de Quintanalara cabe situarlas en los siglos XVIII y XIX.

La ollitas (CV.3) son recipientes de perfil continuo globular, borde reentrante, labio redondeado y fondo ligeramente cóncavo. Están provistas de una pequeña asa de cinta que parte del labio y termina en la zona central del cuerpo. La cocción es oxidante o mixta, y están realizadas en pasta de color rojizo con presencia de desgrasantes cuarcíticos y calizos finos. El vidriado es amarillo, amarillo verdoso y melado, muy irregular y parcial, tanto al interior como al exterior. Perfiles similares han sido documentados en Basardilla (Segovia) con una cronología del siglo XVIII (Cruz, 2008: 35).

\subsection{Cerámica común sin vidriar (CS)}

Encontramos un único ejemplar de cerámica común sin vidriar (Fig. 5), un pequeño cuenco (CS.1) cocido en atmósfera mixta y realizado en pasta con abundantes y finos desgrasantes micáceos. El perfil es sinuoso abierto, de cuello corto pero bien definido, borde exvasado, labio redondeado y fondo plano. Cronológicamente podría remontarse al siglo XVII.

Desde el punto de visita cronológico, el repertorio cerámico de Quintanalara se encuadra fundamentalmente en el siglo XVIII aunque, como se ha visto, se documentan algunas piezas características de producciones del siglo XVII y otras del siglo XIX. En relación a la loza, aunque algunos platos tipo Villafeliche presentes en la colección comienzan a fabricarse en el siglo $X V I I$, la ausencia de recipientes de la serie talaverana tricolor, de enorme difusión en este siglo y presentes en contextos similares al analizado -osario de la iglesia de San Andrés de Cameros (La Rioja) (Sáenz, 1998), osario de la iglesia de Santa Eulalia de Palenzuela (Palencia), ermita de la Virgen del Vallejo de Alcozar (Soria), iglesia de San Salvador (Valladolid) o iglesia de Santa Juliana de Villarmentero (Valladolid) (Cruz, 2010-12)invita a pensar que la fecha de inicio de la andadura del repertorio documentado se situaría no antes de finales de la centuria. Por otro lado, las lozas de medio baño decoradas con óxido de cobre que también integran el repertorio, están presentes en los alfares salmantinos desde el XVII, pero alcanzan su mayor difusión en la centuria siguiente, a mediados de la cual comienzan a fabricarse en otros centros como los de la ciudad de Zamora. Por último, al recipiente de cerámica común sin vidriar CS.1 cabría atribuir cierta antigüedad, pero siempre dentro de los siglos XVII o XVIII. Respecto a la cronología final del repertorio, ciertas lozas y recipientes vidriados pueden enmarcarse en el siglo XIX, momento en el posiblemente desaparece la tradición en Quintanalara como ya se ha mencionado. 

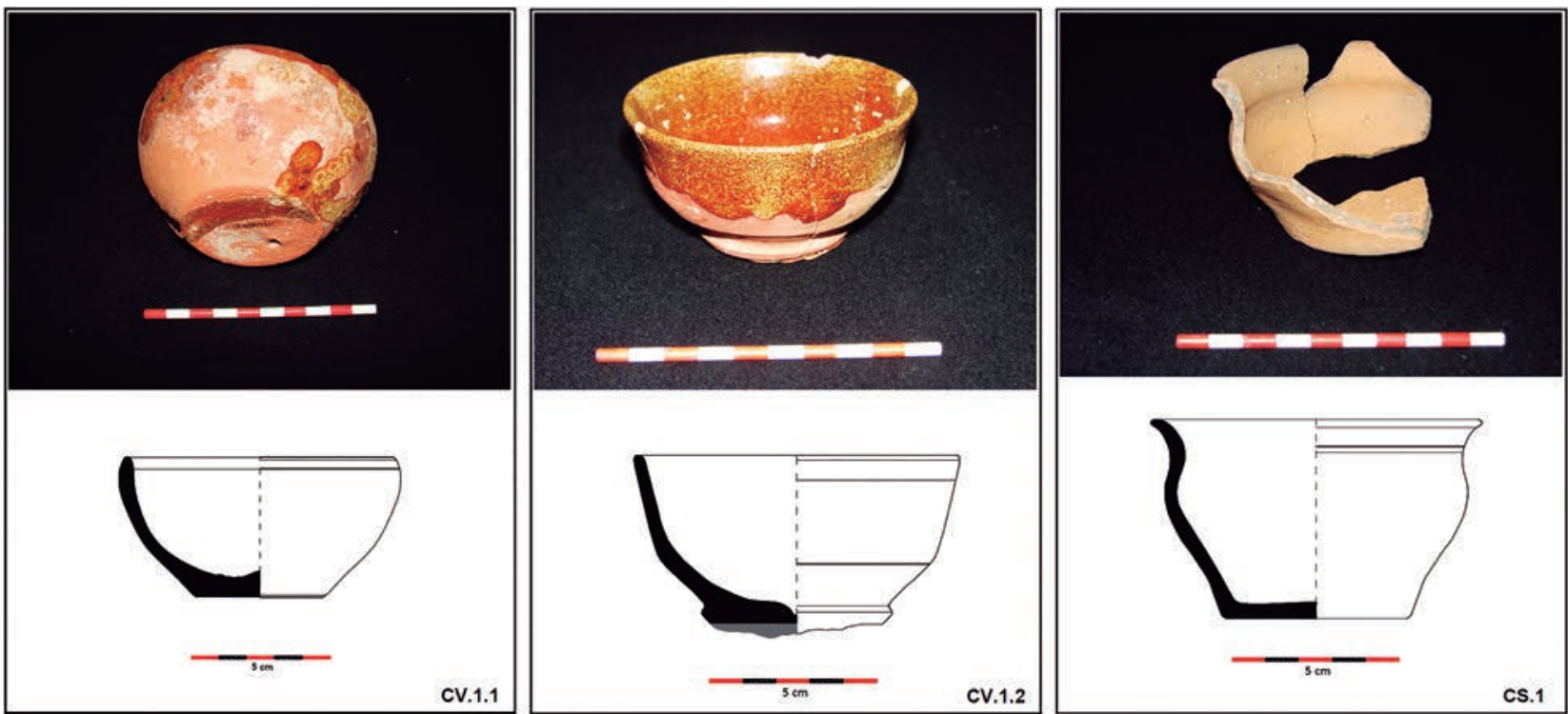

cV.1.1
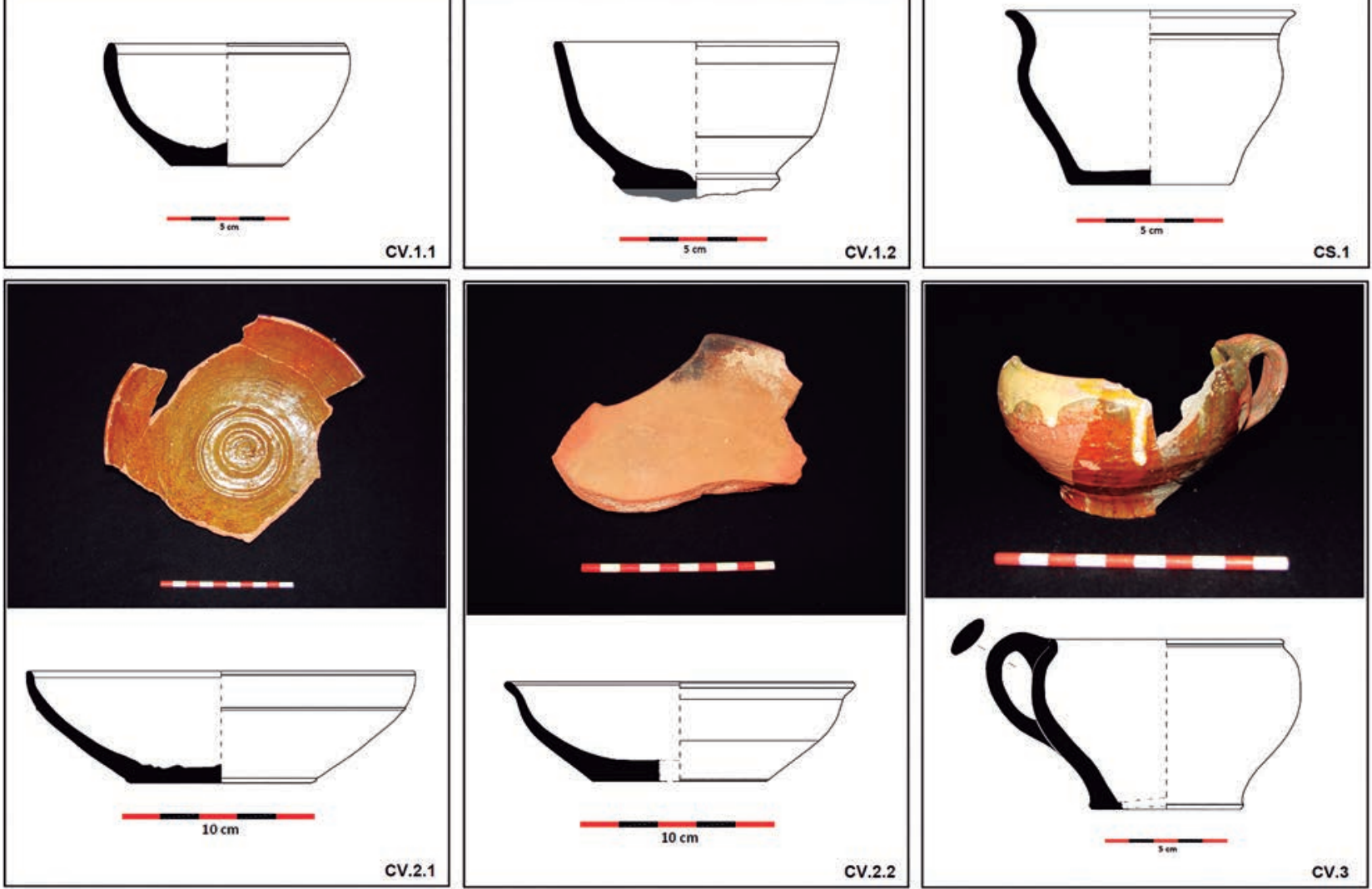

Fig. 5. Cerámica común vidriada (CV) y cerámica común sin vidriar (CS) procedente del osario de la iglesia de Quintanalara (Burgos). Dibujos de Margarita Alonso/ Common glazed pottery (CV) and common unglazed pottery (CS) from the ossuary of the church of Quintanalara (Burgos). Drawings of Margarita Alonso.

El marco cronológico está en sintonía con los datos recapitulados sobre el osario mediante la consulta del Libro de Fábrica de la iglesia parroquial. La primera cita documental es del siglo XVII y está relacionada con un gasto de piedra y cal realizado en 1680. Cinco años más tarde, en 1685, se anota un nuevo gasto en piedra "para la osera que hacen" varios oficiales. Ya a finales del siglo XVIII, en 1799, se anotan "Ciento treinta y tres reales y veinte y un maravedís de costo de la Huesera nueva y de dos balaustres que se añadieron a la reja nueva de la sacristía".

\section{CONCLUSIONES}

Aunque el uso de recipientes con sal en el velatorio o durante la celebración de las exequias fue una práctica muy extendida en la Península desde el siglo XVI y hasta principios del siglo XX, como lo atestiguan los estudios etnológicos y arqueológicos, es muy llamativa la ausencia de referencias sobre el ritual en la documentación histórica, particularmente durante el siglo XVIII cuando la tradición debió estar en pleno apogeo.La sociedad de la época, tanto rural como urbana, estaba marcadamente condicionada por la religión y la superstición que se vivían profundamente y marcaban la pauta de la vida del individuo y de la comunidad. Los platos y cuencos de sal forman parte de ese fervor religioso que atañe particularmente a la muerte, y donde símbolo, mito y rito se aúnan para propiciar el tránsito del alma del difunto al más allá. 


\section{AGRADECIMIENTOS}

Gracias a D. Rubén Heras Gil, alcalde de Quintanalara (Burgos), por el interés y la ayuda prestados. Trabajo financiado por la Junta Vecinal de Quintanalara (Burgos) y la Diputación Provincial de Burgos dentro del programa Proyectos de excavación, prospección y documentación del Patrimonio Arqueológico y Paleontológico de la provincia de Burgos. Ejercicio 2017 (BDNS: 322258), "Rituales funerarios durante la Edad Moderna: los platos y cuencos de sal de Quintanalara (Burgos)".

\section{BIBLIOGRAFÍA}

Alonso-Fernández, C., 2008. Excavación arqueológica de los sepulcros de la iglesia de Nuestra Señora de Villahoz (Burgos). Informe depositado en el Servicio Territorial de Cultura de la Junta de Castilla y León en Burgos, Burgos.

Álvaro, M.I., 1983. La cerámica en el ciclo humano. La amplia función de la cerámica aragonesa. Temas de Antropología Aragonesa 1, 146-158.

Álvaro, M.I., 2003. Cerámica Aragonesa, vol. III. Ibercaja, Zaragoza.

Aparicio, D., 2002. Sociedad y ciclo vital en una aldea soriana: Alcozar, Cuadernos de Etnología Soriana 9. Disponible en: http://www.alcozar.net/etnografia/sociedad.htm. Fecha de acceso: 21 jun. 2018.

Ateneo Literario, Científico y Artístico de Madrid, 1901. Circular y Cuestionario. Información promovida por la Sección de Ciencias Morales y Políticas en el curso 1901 á 1902. Est. Tipográfico Sucesores de Rivadeneyra, Madrid.

Azero, M. de, 1736. Tratado de los funerales y de las sepulturas. Imprenta Real, Madrid.

Barandiaran, J.M. de, Manterola, J.M. (dirs.), 1995. Ritos funerarios en Vasconia. Etniker Euskalerria, Bilbao. Atlas Etnográfico de Vasconia10.

Belido, A., 2006. Catálogo temático de los Fondos Etnográficos. Museo Numantino. Junta de Castilla y León, Valladolid.

Blanco, J.F., 2005. La muerte dormida. Cultura funeraria en la España tradicional. Universidad de Valladolid, Valladolid.

Bosch, B., 1713. Prácticas de visitar a los enfermos y ayudar a bien morir. Imprenta de Francisco de Villa-Diego, Madrid.

Brand, J., 1815. Popular antiquities: chiefly illustrating the origin of our vulgar customs, ceremonies and superstitions. Nichols, Son and Bentley, London.

Catecismo Romano Promulgado por el Concilio de Trento, edición de 1926 comentada por A.M. Gubinanas. Editorial Litúrgica Española, Barcelona.

Cerezal Calvo, M., 1908. Diario de lo ocurrido en el Real Sitio de El Escorial durante la invasión francesa. La Ciudad de Dios LXXVI, 55-107.

Charro, A., 1998. Sal ¿mito o superstición? Revista de Folklore 214, 124-133.

Chevalier, J., Gheerbrant, A., 1990. Dictionnaire des Symboles. Éditions Robert Laffont, Paris.

Cruz, P., 2008. Un interesante conjunto cerámico del siglo XVIII procedente de la iglesia de San Bartolomé de Basardilla (Segovia). Estudios del Patrimonio Cultural 00, 20-31.
Cruz, P., 2010-12. La sal como ofrenda en los rituales mortuorios. Nuevas perspectivas de estudio. Sautuola XVI-XVII, 561-579.

Díaz, O., González, S., 2005. El ciclo de la vida. Pasajes y rutas del Quijote. Junta de Comunidades de Castilla-La Mancha, Toledo.

Domínguez Moreno, J.M., 1989. La muerte en Extremadura: Apuntes etnográficos. Revista de Folklore 108, 183-187.

Encyclopaedia Britannica, 1911. Eleventh Edition, Volume XXVIII. Cambridge University Press, London.

Erkoreka, A., 2005. Mal de ojo: una creencia supersticiosa remota, compleja y aún viva. Munibe Antropologia-Arkeologia 57, 391-400.

Fernández, I., 1997. De la vida, del amor y la muerte. Burgos y su provincia en la encuesta de 1901-1902 del Ateneo de Madrid. Librería Berceo, Burgos.

Flores, F.J., 2000. Diccionario de supersticiones y creencias populares. Alianza Editorial, Madrid.

García de Bayona, D.J., 1633. De la veneración del Smo. Sacramento de la Extremaunción. Doctrina para conocer las tentaciones del demonio en la hora de la muerte y vencerlas para morir en la gracia de Dios. Imprenta de Francisco Martínez, Madrid.

García Benito, A., 2004. Cerámica tradicional de Peñafiel. Diputación Provincial, Valladolid.

García Fernández, M., 2004. Cultura material y religiosidad popular en el seno familiar castellano del siglo XVIII. Cuadernos Dieciochistas 5, 97-121.

García Hinojosa, P., 2010. Simbolismo, religiosidad y ritual barroco. La muerte en Teruel en el siglo XVII. Tesis Doctoral, Universidad de Zaragoza.

García Lorca, F., 1996. Obras completas. Edición de Miguel García Posada, volumen IV. Galaxia Gutenberg - Círculo de Lectores, Barcelona.

García Rozas, R., 1999. Museo de Zamora: guía. Junta de Castilla y León, Valladolid.

Gómez, P., 1802. Instrucciones mortuorias o reglas para los enterramientos y funerales. Imprenta de la Casa de Misericordia, Cádiz.

González-Hontoria, G., 1991. El arte popular en el ciclo de la vida humana. Testimonio Compañía Editorial, Madrid.

Guiance, A., 1998. Discursos sobre la muerte en la Castilla Medieval (siglos VII-XV). Junta de Castilla y León, Valladolid.

Herbermann, C.G., Pace, E.A., Pallen, C.B., Shahan, T.J., Wynne, J.J., (eds.), 1916. The Catholic Encyclopedia, volume 13. Robert Appelton Company, New York.

Hernández, E., Martínez, R., 2014. Església de Sant Cristòfor Màrtir: les restes de 200 anys d'història. Picassent. Festes Majore, 37-43. Ajuntament de Picassent, Valencia.

Herrero, G., Merino, C., 1996. Costumbres populares segovianas de nacimiento, matrimonio y muerte. Encuesta del Ateneo 1901-1902. Diputación Provincial de Segovia, Segovia.

Home, G., 1915. The evolution of an English Town. Being the story of the ancient town of Pickering in Yorkshire from Prehistoric times up to the year of our Lord Nineteen Hundred, J.M. Dent \& Sons Ltd, London. 
Jordán, J.F., Iniesta, J.A., 1996. Costumbres funerarias en la serranía de Albacete. Al-Basit 39, 317-345.

López, J., Lombardía, C., 1998. Costumbres de nacimiento, matrimonio y muerte en Asturias. Encuesta del Ateneo de Madrid 1901-1902. Ayuntamiento de Gijón, Asturias.

Lorenzo, F.J., 1991. Muerte y ritual en la Edad Moderna: el caso de Zamora. Universidad de Salamanca, Salamanca.

Lorenzo, M.R., 1999. Alfares en Salamanca. Centro de Cultura Tradicional, Salamanca.

Lucendo, D., Retuerce, M., Melero, M., 2015. La cerámica del Quijote a través de dos intervenciones manchegas: el silo de la calle Morería en Ciudad Real y la iglesia de Socuéllamos. In: Alía, F., Anaya, J., Mansilla, L., Sánchez, J., (Dirs.), I Congreso Nacional Ciudad Real y su provincia, Tomo III, 127-140. Instituto de Estudios Manchegos, Ciudad Real.

Madoz, P., 1845-1850. Diccionario Geográfico-Estadístico-Histórico de España y sus posesiones de ultramar. Edición facsímil de 1984. Ámbito Ediciones, Valladolid

Magaña, J., Guerra, R.A., 2011. Ofrenda a muertos en México. Presente y Pasado. Revista de Historia 31, 37-48.

Marco, M., 2010. Ritos, historias, costumbres, objetos y cosas en torno a los difuntos. Cuadernos de etnología de Guadalajara 42, 11-44.

Mariño, X., 2000. Antropoloxía de Galicia. Edicións Xerais de Galicia, Vigo.

Martín-Bueno, M., Erice, R., Sáenz, M.P., 1987. La Alfajería. Investigación arqueológica. Cortes de Aragón, Zaragoza.

Martínez, E., 1994. La alfarería en La Rioja: desde el siglo XVI al siglo XX. Gobierno de La Rioja, Logroño.

Mateo, M.A., 1993. Ritos funerarios en la Huerta de Murcia: Aljucer. In: Álvarez, L., Flores, F., González, A., (Eds.), Cultura y Sociedad en Murcia, 359-375. Universidad de Murcia, Murcia.

Moreda, J., Martín, M.A., Fernández, A., González, L., 1998. El Monasterio de San Benito El Real y Valladolid. Arqueología e historia. Ayuntamiento de Valladolid, Valladolid.

Moreno, M., 1995. Costumbres acerca de los difuntos en Los Pedroches (Córdoba). Gaceta de Antropología 11. Disponible en: «http://www.ugr.es/ pwlac/G11_11Manuel_Moreno_Valero.html». Fecha de acceso: 21 jun. 2018.

Museo Etnográfico de Castilla y León, 2004. Museo Etnográfico de Castilla y León. Junta de Castilla y León, Valladolid.

Obispado de Valladolid, 1634. Constituciones sinodales hechas y promulgadas en el primer sínodo que se celebra en la ciudad y obispado de Valladolid el día 26 de octubre de 1634, Reimpresión de 1803. Imprenta de Pablo Miñón, Valladolid.

Padilla, J.I., Rueda, K.A., 2011. La pileta del despoblado medieval de Revenga (Burgos): a propósito del lavado ritual de los difuntos y sus evidencias arqueológicas. Pyrenae 42(1), 67-100.

Parroquia de San Esteban de Quintanalara, 1606-1706, 17671915. Libro de Fábrica. Archivo Diocesano de Burgos. Signatura $2 / \mathrm{A}-1,2$.

Pitarch, A.J., Connors, M. E., 2005. La colección de cerámica de Alcora. The hispanic society of America. Fundación Blasco de Alagón, Barcelona.

Pleguezuelo, A., 2001. Lozas 'contrahechas', ecos de Talavera en la cerámica española. En: Cerámica de Talavera de la
Reina y Puente del Arzobispo en la colección Bertrán y Musitu [exposición], 37-53. Juan Antonio Bertrán, Barcelona.

Pleguezuelo, A., 2002. Luces y sombras sobre las lozas Talavera. En: Lozas y azulejos de la Colección Carranza v. I, 321 272. Museo Santa Cruz de Toledo, Toledo.

Polanco, C., 2001. Muerte y sociedad en Burgos en el siglo XVI. Diputación Provincial de Burgos, Burgos.

Real Academia de la Historia, 1786. Informe dado al Consejo por la Real Academia de la Historia en 10 de junio de 1783 sobre la disciplina eclesiástica antigua y moderna relativa al lugar de las sepulturas. Oficina de Don Antonio Sancha, Madrid.

Rodriguez, J.M., 2004. Ritos de muerte en Torre Pacheco. Revista Murciana de Antropología 11, 189-208.

Sáenz, P., 1998. Hallazgo de un conjunto cerámico en la iglesia parroquial de San Andrés de Cameros (Lumbreras, La Rioja). Estrato 9, 71-78.

Salillas, R., 1905. La fascinación en España: brujas, brujería, amuletos. Estudio hecho con la información promovida por la Sección de Ciencias Morales y Políticas del Ateneo de Madrid. Imprenta a cargo de Eduardo Arias, Madrid.

Seseña, N., 1997. Cacharrería popular. La alfarería de basto en España. Alianza Editorial, Madrid.

Sevillano, F.V., 1978. Testimonio arqueológico de la provincia de Zamora. Instituto de Estudios Zamoranos Florián de Ocampo, Zamora.

Sikes, W., 1880. British goblins: welsh folk-lore, fairy mythology, legends and traditions. Sampson Low, Marston, Searle \& Rivington, London.

Unoveinte, 2010. Excavación y control arqueológicos en la iglesia de San Nicolás de Bari, en Sinovas (Aranda de Duero, Burgos). Informe depositado en el Servicio Territorial de Cultura de la Junta de Castilla y León, Burgos.

Villanueva, O., 2011. La ollería y la alcallería en la cuenca del Duero a lo largo de la Edad Media y Moderna. In: Coll, J. (Coord.), Manual de cerámica medieval y moderna, 87-115. Colegio Oficial de Doctores y Licenciados en Filosofía y Letras y en Ciencias, Madrid.

Villar, C., 2003. Creencias y costumbres populares (Campo de Montiel). Revista de Folklore 274, 136-144.

Wörrle, B., 1999. De la cocina a la brujería. La sal entre indígenas y mestizos en América Latina. Abya-Yala, Ecuador.

Xandri, J., González, J.R., 2008. Treballs arqueològics realitzats a l'esglesia parroquial de Sant Nicolau de Bellpuig. Urtx 22, 197-239.

Zaparaín Yáñez, M.J., 1993. Los cementerios bajo el Reformismo llustrado. Su problemática en Burgos (1750-1813). Boletín de la Institución Fernán González 207, 399-410. 